\title{
Kinetika Reaksi Poliesterifikasi Hidrolisat Shellac dan Anhidrida Ftalat Ditinjau Dari Reaktivitas Gugus Hidroksil
}

\author{
Lestari Hetalesi Saputri $^{1 *}$, Rochmadi ${ }^{1}$, Budhijanto ${ }^{2}$ \\ ${ }^{1}$ Program Studi Teknik Kimia, Politeknik LPP, Jl LPP No 1A, Balapan, Yogyakarta 55222 \\ ${ }^{2}$ Jurusan Teknik Kimia, Universitas Gadjah Mada, Yogyakarta \\ *email: lestari_h@politeknik-lpp.ac.id atau titatekim@gmail.com
}

\begin{abstract}
This research presents polyesterification kinetics for shellac hydrolizate-phtalic anhydride. The polyesterification kinetics is proposed by assuming that the reaction in ideal system, whereas the reactivity of the $\mathrm{OH}$ groups are considered different. Polyesterification was started from purification of shellac by hydrolisis process. Hydrolisis was done by dissolving seedlac into $\mathrm{NaOH}$ solution and acidification with $\mathrm{HCl}$. Polyesterification was conducted by reacting shellac hydrolizate with phtalic anhydride. Both of these materials were reacted in a three necked flask under vacuum condition. The reaction was conducted in temperature range of $130-170^{\circ} \mathrm{C}$ and samples were taken every 30 minutes for a total of 5 hours, to determine the $\mathrm{COOH}$ concentration by titration. The investigation of reaction kinetic showed that reaction model could describe the kinetic of polyesterification shellac hydrolzate-phthalic anhydride, especially for temperatures below $150^{\circ} \mathrm{C}$.
\end{abstract}

Keywords: polyesterification, shellac hydrolizate, ideal system, reaction kinetic

\section{Pendahuluan}

Polyester resin adalah salah satu jenis polimer yang biasanya diaplikasikan untuk cat dan coating. Polimer ini diperoleh melalui proses poliesterifikasi, yaitu proses polimerisasi kondensasi yang menggabungkan dua jenis gugus utama yaitu karboksil dan hidroksil [1]. Polyester resin yang banyak dipakai selama ini berupa polyester resin sintetis yang mempunyai sifat tahan lama dan sukar terdegradasi. Oleh karena itu, penelitian-penelitian baru untuk memproduksi polyester resin yang lebih ramah lingkungan sangat diperlukan. Salah satu upaya yang telah dilakukan untuk menciptakan produk polyester resin tersebut yaitu melalui modifikasi poliester dari bahan alam.

Pada penelitian ini, bahan alam yang digunakan adalah shellac. Shellac adalah polimer alam yang berasal dari sekresi kutu lak yang memiliki sifat mudah terdegradasi, mempunyai sifat adhesi yang baik dan sangat cocok sebagai pelapis [2]. Selain itu, bahan ini juga banyak tersedia di alam,tidak beracun dan bersifat renewable [3]. Penelitian untuk memodifikasi shellac pernah dilakukan oleh Sontaya dkk [4]. Hasilnya penelitiannya ditemukan adanya peningkatan bilangan asam, tingkat kelarutan dan sifat fleksibitas pada shellac. Sifat-sifat ini hanya cocok untuk aplikasi coating obat-obatan. Selain itu, penelitian modifikasi lainnya yaitu melalui penambahan anhidrida ftalat yang pernah dilakukan oleh Danuch dkk [5]. Dengan penambahan anhidrida ftalat, ditemukan adanya perbaikan sifat ketahanan panas pada shellac namun belum pada sifat - sifat mekanis lainnya. Penelitian Danuch [5] dilakukan tanpa didahului proses hidrolisis.

Penelitian ini merupakan perpaduan dari penelitian Sontaya dkk [4] dan Danuch dkk [1] [5], dimana struktur kimia poliester shellac dimodifikasi melalui proses hidrolisis terlebih dahulu dan kemudian dilanjutkan dengan proses poliesterifikasi melalui penambahan anhidrida ftalat. Modifikasi ini ditujukan untuk meningkatkan sifat mekanis bahan seperti sifat kekuatan tarik, kekerasan bahan dan daya serap terhadap air, sehingga nantinya akan memberikan nilai tambah pada aplikasi produknya yaitu sebagai coating, terutama untuk coating kayu. Selain karakterisasi sifat mekanis, yang tidak kalah penting dalam pembuatan suatu produk adalah penentuan kondisi proses (dalam hal ini proses inti yaitu poliesterifikasi) melalui peninjauan kinetika reaksi. Kinetika reaksi diperlukan dalam perancangan peralatan poliesterifikasi, terutama perancangan reaktor, guna menghasilkan reaksi poliesterifikasi yang baik pada skala keteknikan sehingga nantinya dapat di scale up ke skala industri.

Oleh karena itu, penelitian ini diarahkan pada kinetika reaksi poliesterifikasi antara shellac dan anhidrida ftalat. Kinetika reaksi dipelajari dengan menganalisis sisa gugus $\mathrm{COOH}$ hasil proses poliesterifikasi antara shellac (komposisi utamanya yaitu aleuritic acid dan jalaric acid) dengan anhidrida ftalat. Analisis gugus 
diperlukan untuk mempertimbangkan model kinetika yang sesuai untuk proses poliesterifikasi shellacanhidrida ftalat, sehingga nantinya akan berguna dalam proses pembuatan produk polyester resinnya.

\section{Metodologi}

Bahan penelitian antara lain: seedlac (sekresi kutu lak) albasia dari daerah Ciamis Jawa Barat, $\mathrm{HCl}$ pekat merk JT Baker, alkohol 96\% dari CV Genera Labora, serta anhidrida ftalat, $\mathrm{NaOH}$, asam asetat anhidrida dan piridin merk KgaA. Proses hidrolisis menggunakan gelas beker, termometer, magnetik stirer, kertas saring, desikator vakum dan pompa vakum. Proses poliesterifikasi dilakukan dalam labu leher tiga yang dilengkapi pemanas mantel, tabung nitrogen, termometer, vacuum gauge dan pompa vakum.

Proses hidrolisis dilakukan dengan cara: shellac dan larutan $\mathrm{NaOH} 10 \%$ dalam jumlah tertentu dimasukkan ke dalam gelas beker, kemudian dilakukan pengadukan dan pemanasan selama \pm 30 menit pada suhu $60^{\circ} \mathrm{C}$. Setelah itu, larutan didinginkan dan disaring. Filtrat hasil hidrolisis yang berupa garam karboksilat diasamkan dengan $\mathrm{HCl}$ dan diaduk hingga terbentuk endapan. Endapan disaring dan sebelum digunakan untuk proses poliesterifikasi, terlebih dahulu dilarutkan dalam alkohol $96 \%$ untuk dicek pH-nya. Apabila sudah dipastikan kondisi asamnya, endapan dipanaskan pada suhu $100^{\circ} \mathrm{C}$. Sementara itu, untuk proses poliesterifikasi dilakukan dengan cara: shellac hasil hidrolisis dalam jumlah tertentu dimasukkan ke dalam labu leher tiga, kemudian dipanaskan sampai suhu $100^{\circ} \mathrm{C}$. Setelah suhu tercapai, anhidrida ftalat ditambahkan. Cuplikan diambil setiap selang waktu 30 menit untuk dianalisis kandungan gugus karboksilatnya sampai waktu reaksi 5 jam. Perbandingan mol gugus $\mathrm{COOH} / \mathrm{OH}$ ditetapkan 1,5:1.

\section{Pendekatan Model Kinetika Poliesterifikasi}

Penentuan model kinetika reaksi didasarkan pada jenis gugus $\mathrm{OH}$ yang bereaksi, yaitu $\mathrm{OH}$ primer dan $\mathrm{OH}$ sekunder pada shellac. Gugus $\mathrm{OH}$ primer (Ap) hanya berasal dari asam aleuritik, sementara $\mathrm{OH}$ sekunder (As) berasal dari asam aleuritik dan asam jalarik. Konstanta kecepatan reaksi disederhanakan menjadi 2 nilai konstanta, yaitu $\mathrm{k}_{1}$ untuk $\mathrm{OH}$ primer yang bereaksi dan $\mathrm{k}_{1}$ untuk $\mathrm{OH}$ sekunder yang bereaksi, sehingga mekanisme reaksinya dapat ditulis sebagai berikut:

$$
\begin{aligned}
& \mathrm{A}_{\mathrm{p}}+\mathrm{B} \stackrel{\mathrm{k}_{1}}{\longrightarrow} \mathrm{A}_{\mathrm{p}} \mathrm{B} \\
& \mathrm{A}_{\mathrm{s}}+\mathrm{B} \stackrel{\mathrm{k}_{2}}{\longrightarrow} \mathrm{A}_{\mathrm{s}} \mathrm{B}
\end{aligned}
$$

Bila dibuat neraca molnya, didapatkan:

$$
\begin{aligned}
& -\frac{\mathrm{dC}_{\mathrm{Ap}}}{\mathrm{dt}}=\mathrm{k}_{1} \mathrm{C}_{\mathrm{Ap}} \mathrm{C}_{\mathrm{B}} \\
& -\frac{\mathrm{dC}_{\mathrm{As}}}{\mathrm{dt}}=\mathrm{k}_{2} \mathrm{C}_{\mathrm{As}} \mathrm{C}_{\mathrm{B}} \\
& \frac{\mathrm{dC}_{\mathrm{B}}}{\mathrm{dt}}=\frac{\mathrm{dC}_{\mathrm{Ap}}}{\mathrm{dt}}+\frac{\mathrm{dC}_{\mathrm{AS}}}{\mathrm{dt}}
\end{aligned}
$$

Data hubungan antara konsentrasi ketiga gugus sisa karboksil yaitu Asam Aleuritat, asam jalarik dan anhidrida ftalat dengan waktu didapatkan dengan menganalisis sisa gugus karboksil pada setiap selang waktu tertentu. Nilai $\mathrm{k}_{1}$ dan $\mathrm{k}_{2}$ ditentukan dengan cara minimasi SSE, yaitu dengan rumus:

$$
\mathrm{SSE}=\sum\left(\mathrm{C}_{\mathrm{COOH} \text { hitung }}-\mathrm{C}_{\mathrm{COOH} \text { data }}\right)^{2}
$$

Nilai CB diperoleh melalui penyelesaian Persamaan (1) sampai dengan Persamaan (3). Sementara itu, Pengaruh suhu terhadap nilai konstanta kecepatan reaksi pada model 1 dan 2 dinyatakan dengan persamaan Arhenius [6].

$$
\mathrm{k}=\mathrm{A} \exp \left(\frac{-\mathrm{E}}{\mathrm{RT}}\right)
$$

Algoritma untuk menghitung nilai $\mathrm{k}_{1}$ dan $\mathrm{k}_{2}$ dari persamaan-persamaan tersebut dapat dilihat pada Gambar 1 . 


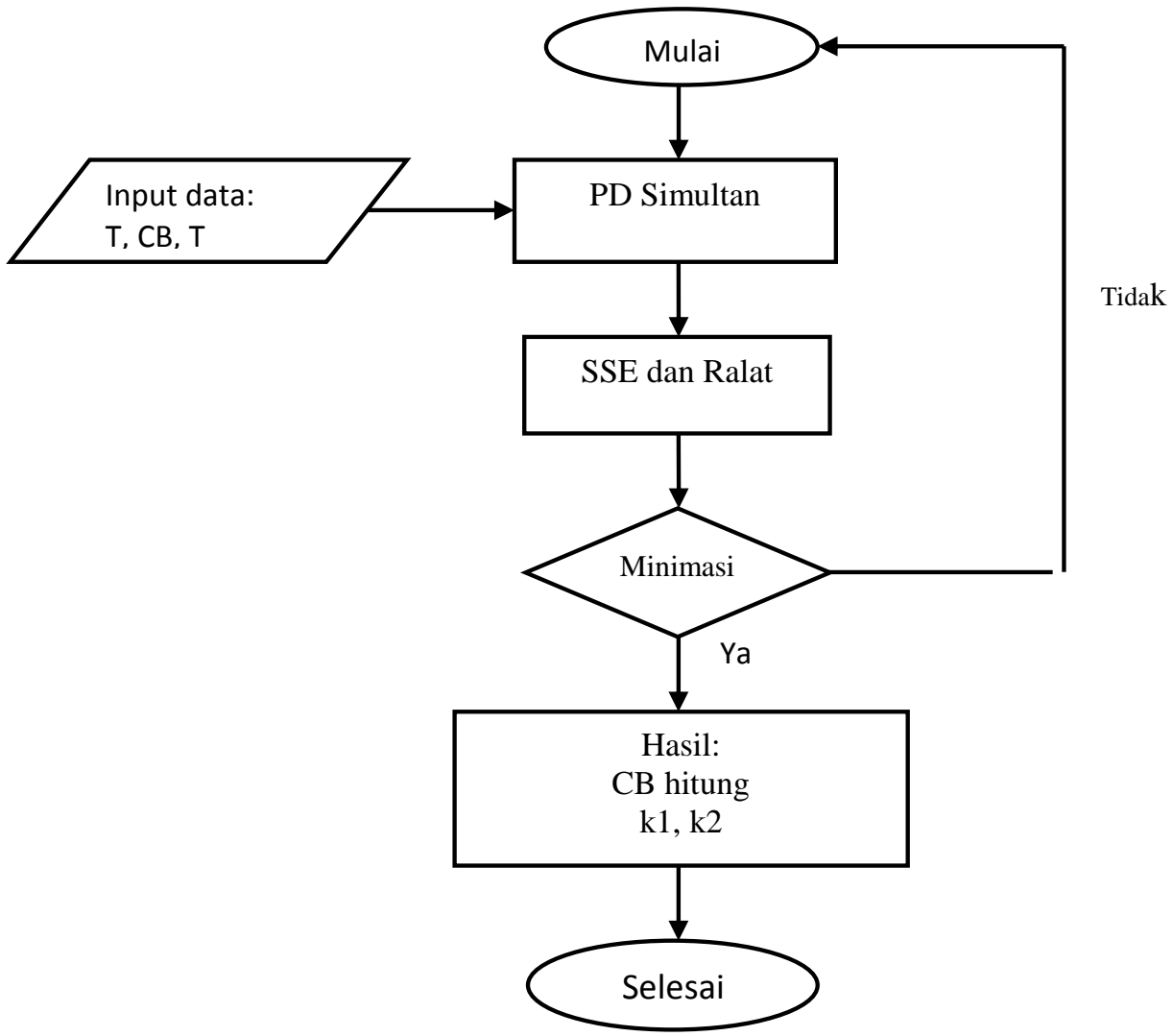

Gambar 1. Algoritma Perhitungan Kecepatan Reaksi

\section{Hasil dan Pembahasan}

Konsentrasi sisa gugus $\mathrm{COOH}$ (mgrek/gram) dari hasil percobaan dan perhitungan pada berbagai suhu dan waktu reaksi untuk perbandingan mol COOH/OH 1,5 dapat dilihat pada Gambar 2.

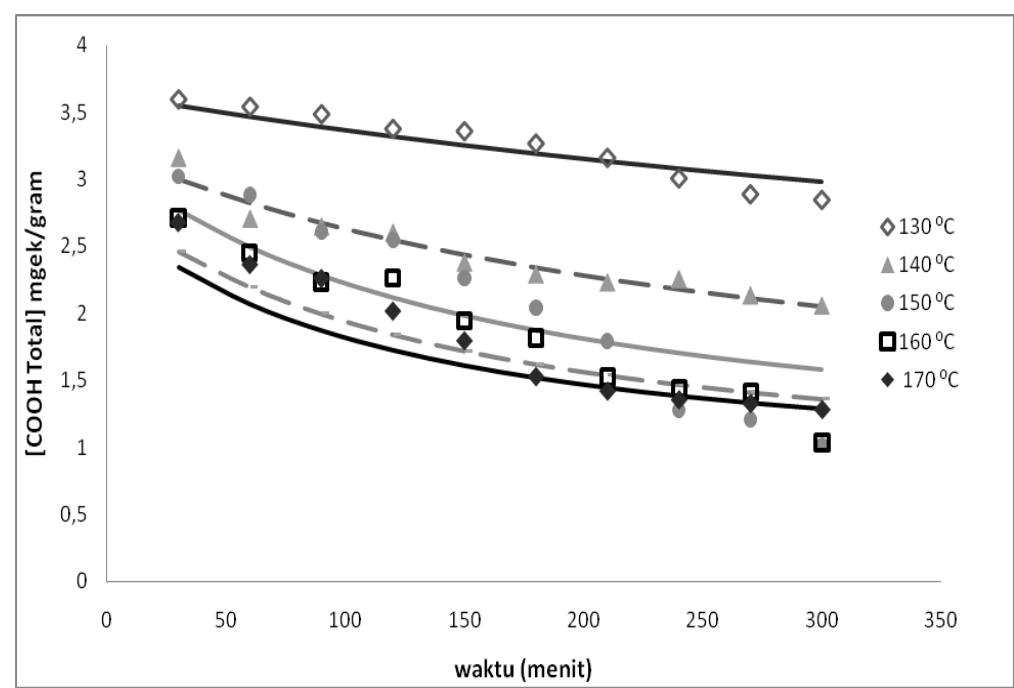

Gambar 2. Hubungan konsentrasi sisa gugus karboksil dengan waktu reaksi pada berbagai suhu

Pada Gambar 2 terlihat bahwa pada waktu reaksi yang tetap, dengan bertambahnya suhu, sisa karboksil semakin sedikit. Suhu tinggi menyebabkan molekul-molekul pereaksi bergerak lebih cepat, sehingga tumbukan antar molekulnya semakin sering terjadi dan reaksi polimerisasinya menjadi lebih cepat [7]. Bila dilihat pada Gambar 2, terjadi penyimpangan yang cukup besar pada reaksi poliesterifikasi di suhu $150^{\circ} \mathrm{C} \mathrm{ke}$ 
atas. Ini menandakan bahwa pada suhu yang cukup tinggi, reaktivitas molekul sudah banyak mengalami perubahan dan diduga pula akibat pengaruh $\mathrm{OH}$ sekunder yang sudah cukup tinggi. Gugus $\mathrm{OH}$ sekunder yang mengalami peningkatan reaktivitas berakibat pada perubahan viskositas. Viskositas larutan untuk suhu di atas $150^{\circ} \mathrm{C}$ cenderung mengalami kenaikan karena efek terjadinya crosslink, sehingga perpindahan massa antara shellac dan anhidrida ftalat menjadi lebih lambat. Ini didukung oleh teori yang dikemukakan oleh Malcolm [8], mengatakan bahwa apabila struktur dan percabangan rantai polimer semakin banyak terbentuk, maka viskositas polimer tersebut akan menjadi semakin sensitif terhadap perubahan-perubahan suhu. Jadi dapat dikatakan bahwa model kinetika reaksi yang diajukan cukup menggambarkan dengan baik untuk proses poliesterifikasi shellac-anhidrida ftalat di bawah suhu $150^{\circ} \mathrm{C}$. Akan tetapi, kurang tepat untuk suhu di atasnya. Sementara untuk kecepatan reaksi, dapat diwakilkan dari hasil simulasi konstanta kecepatan reaksi yang akan ditunjukkan pada Tabel 1.

Tabel 1. Hasil optimasi konstanta kecepatan reaksi (dalam g/mgek.menit)

\begin{tabular}{|c|c|c|}
\hline Suhu, ${ }^{\circ} \mathbf{C}$ & $\mathbf{k}_{1}$ & $\mathbf{k}_{\mathbf{2}}$ \\
\hline $\mathbf{1 3 0}$ & $8,1 \times 10^{-4}$ & $2,1 \times 10^{-4}$ \\
\hline $\mathbf{1 4 0}$ & $2,0 \times 10^{-3}$ & $8,2 \times 10^{-4}$ \\
\hline $\mathbf{1 5 0}$ & $2,2 \times 10^{-3}$ & $2,0 \times 10^{-3}$ \\
\hline $\mathbf{1 6 0}$ & $3,2 \times 10^{-3}$ & $2,6 \times 10^{-3}$ \\
\hline $\mathbf{1 7 0}$ & $5,5 \times 10^{-3}$ & $2,7 \times 10^{-3}$ \\
\hline
\end{tabular}

Pada Tabel 1, nilai konstanta kecepatan reaksi pembentukan rantai lurus $\left(\mathrm{k}_{1}\right)$ bernilai lebih besar daripada nilai konstanta kecepatan reaksi pembentukan rantai cabang $\left(\mathrm{k}_{2}\right)$. Nilai $\mathrm{k}$ yang lebih besar menunjukkan reaksi yang lebih cepat berlangsung. Perbedaan kecepatan reaksi ini disebabkan karena faktor posisi, dimana gugus $\mathrm{OH}$ primer terletak di ujung rantai sehingga lebih mudah bereaksi bila dibandingkan dengan $\mathrm{OH}$ sekunder yang posisinya di tengah rantai. Selain itu, dari Tabel 1 juga terlihat bahwa kecepatan reaksi untuk kedua pembentukan rantai, baik rantai lurus maupun rantai cabang cenderung mengalami kenaikan seiring dengan meningkatnya suhu reaksi poliesterifikasi. Nilai konstanta kecepatan reaksi untuk pembentukan rantai lurus mengalami kenaikan yang cukup tinggi pada suhu reaksi $130^{\circ} \mathrm{C}$ ke suhu $140^{\circ} \mathrm{C}$. Kenaikannya yaitu sebesar 2,5 kali. Namun setelah suhu $150^{\circ} \mathrm{C}$ nilainya mengalami kenaikan rata - rata sebesar 1,6 kali. Sementara untuk pembentukan rantai cabang, kenaikan nilai k yang tinggi terjadi pada suhu $140^{\circ} \mathrm{C}$ ke suhu $150^{\circ} \mathrm{C}$ yaitu sebesar 2,4 kali. Akan tetapi setelah suhu $150^{\circ} \mathrm{C}$, perubahan nilai k cenderung tetap. Kecepatan reaksi $\mathrm{k}_{1}$ juga didukung oleh hasil energi aktivasinya yang lebih kecil yaitu sebesar 7556,2 kal/mol, bila dibandingkan dengan energi aktivasi $\mathrm{k}_{2}$ yang bernilai $8071,8 \mathrm{kal} / \mathrm{mol}$. Besarnya nilai energi aktivasi untuk $\mathrm{k}_{2}$ juga membuktikan bahwa pembentukan polimer rantai lurus memang lebih cepat terjadi bila dibandingkan dengan pembentukan polimer rantai cabang.

\section{Kesimpulan}

Dari penelitian yang telah dilakukan, model kinetika di atas dapat menggambarkan dengan baik untuk proses poliesterifikasi shellac-anhidrida ftalat di bawah suhu $150^{\circ} \mathrm{C}$, akan tetapi tidak cukup baik untuk suhu poliesterifikasi $150^{\circ} \mathrm{C}$ ke atas. Pada kisaran suhu $150^{\circ} \mathrm{C}-170^{\circ} \mathrm{C}$, berat molekul polimer yang terbentuk diperkirakan sudah cukup tinggi dengan kecepatan pembentukan rantai lurus lebih besar daripada kecepatan pembentukan rantai cabang.

\section{Ucapan Terimakasih}

Penulis mengucapkan terima kasih kepada Direktorat Jenderal Pendidikan Tinggi Kementerian Pendidikan Nasional yang telah membiayai penelitian ini melalui Program Hibah Kompetisi Institusi (PHKI), Bapak Mujiyono atas penyediaan seedlac, serta kepada Jurusan Teknik Kimia, Fakultas Teknik, Universitas Gadjah Mada dan Program Studi Teknik Kimia, Politeknik LPP Yogyakarta.

\section{Daftar Notasi}

A $\quad=$ faktor frekuensi tumbukan, g/mgek.menit

$\mathrm{C}_{\mathrm{Ap}}=$ konsentrasi sisa gugus $\mathrm{OH}$ primer pada shellac, mgek/gram

$\mathrm{C}_{\mathrm{As}}=$ konsentrasi sisa gugus $\mathrm{OH}$ sekunder pada shellac, mgek/gram

$\mathrm{C}_{\mathrm{B}} \quad=$ konsentrasi sisa gugus $\mathrm{COOH}$ total, mgek/gram

$\mathrm{E} \quad=$ energi aktivasi, $\mathrm{kal} / \mathrm{mol}$

$\mathrm{k}=$ konstanta kecepatan reaksi, g/mgek.menit 
Chemica

Volume 2, Nomor 2, Desember 2015, 61-65

ISSN: $2355-8776$

$\mathrm{R} \quad=$ konstanta gas, $\mathrm{kal} / \mathrm{mol} . \mathrm{K}$

$\mathrm{T} \quad=$ suhu, $\mathrm{K}$

\section{Daftar Pustaka}

[1] Flory, Paul J. 1953. Principles of Polymer Chemistry. Cornell University Press, New York.

[2] Mujiyono, Jamasri, Santoso, B.R., Sutopo G. 2010. Rekayasa Biokomposit dari Sekresi Kutu Lak dan Serat Rami. Seminar Nasional Hasil-Hasil Penelitian Teknologi MIPA dan Sekolah Vokasi, Yogyakarta: 421-434.

[3] Sharma, S.K., Shukla, S.K., Vaid, D.N. 1983. Shellac-Structure, Characteristic and Modification. Defence Science (33): 261-271. Delhi.

[4] Sontaya, L., Chutima, L., Maneeluangtana-anan, Jurairat, N., Toshic, O., Yuich, T., Keiji, Y., Satit, P. 2004. Modification of Physicochemical and Mechanical Properties of Shellac by Partial Hydrolisis. International Journal of Pharmaceutical (278): 41-49. Thailand.

[5] Danuch, P., Chutima, L., Manee, L., Jurairat, N., Pornsak, S., Sontaya, L. 2011. Fabrication of Thermally Stabilized Shellac Through Solid State Reaction with Phthalic Anhydride. Material Letters 65: 1241-1244. Thailand.

[6] Fogler, H.S. 1999. Element of Chemical Reaction Engineering. 3rd. Prentice Hall International, Inc, New Jersey.

[7] Haryanto, Rochmadi dan Arief, B. 2005. Kinetika Reaksi Poliesterifikasi Gliserol Asam Adipat. Teknosains, Yogyakarta.

[8] Malcom R.S., (Penerjemah) Sofyan, Iis. 2001. Kimia Polimer. Pradnya Paramita, Jakarta. 